\title{
Autologous Hematopoietic Stem Cell Transplantation in the Treatment of Multiple Sclerosis
}

\author{
Carolina A. Rush, ${ }^{1}$ Harold L. Atkins, ${ }^{2}$ and Mark S. Freedman ${ }^{1}$ \\ ${ }^{1}$ Department of Medicine-Neurosciences, Ottawa Hospital Research Institute, University of Ottawa, Ottawa, \\ Ontario K1H 8L6, Canada \\ ${ }^{2}$ Department of Medicine-Hematology, Ottawa Hospital Research Institute, University of Ottawa, Ottawa, \\ Ontario K1H 8L6, Canada \\ Correspondence: carush@toh.ca
}

\begin{abstract}
Multiple sclerosis (MS) is an autoimmune disorder that typically affects young people during their most productive years, causing irreversible damage and accumulation of disability. Treatments over time have had modest effects at completely controlling or suppressing disease activity, but are generally aimed at controlling early dominating inflammation that, over time, accumulates damage and leads to progressive disability. Some unfortunate patients are destined to deteriorate despite even newer and more effective agents because of the inability of these drugs to fully curb the inflammatory component of the disease. These patients require something more that might be capable of halting the disease process. Using high-intensity myeloablative chemotherapeutic agents, it is now possible to completely remove the peripheral immune system and replace it anew from autologous bone marrow-derived hematopoietic stem cells, purged of disease-causing MS cells. This procedure, referred to as hematopoietic stem cell transplantation (HSCT), produces a new immune system that appears tolerant and no longer attacks the central nervous system (CNS).
\end{abstract}

\begin{abstract}
$M$ ultiple sclerosis (MS) is the most common neurological autoimmune condition currently treated with hematopoietic stem cell transplantation (HSCT). The first experience treating MS, as the primary indication for using HSCT, dates back to the early 1990s (Fassas et al. 1997), yet it continues to spark interest around the world with increasingly more international transplantation groups getting involved. The
\end{abstract}

body of evidence available on the effects of HSCT in MS stems from different sources. Experimental animal studies showed clinical remission after ablative treatment and stem cell transplants (van Gelder and van Bekkum 1993, 1996), and anecdotal reports of patients with MS undergoing allogeneic HSCT for a concomitant malignancy (McAllister et al. 1997; Mandalfino et al. 2000; La Nasa et al. 2004) suggested the

Editors: Howard L. Weiner and Vijay K. Kuchroo

Additional Perspectives on Multiple Sclerosis available at www.perspectivesinmedicine.org

Copyright (C) 2019 Cold Spring Harbor Laboratory Press; all rights reserved; doi: 10.1101/cshperspect.a029082

Cite this article as Cold Spring Harb Perspect Med 2019;9:a029082 
C.A. Rush et al.

effectiveness of immunoablation in the control of MS. Allogeneic stem cell transplantation is more complex, requiring donor stem cells, and, thus, the procedure is fraught with higher rates of morbidity and mortality, including graft-versus-host disease (GVHD) - an event that does not occur when autologous stem cell sources are used-and risks of opportunistic infections from immunosuppressants used to prevent GVHD. Thus, autologous bone marrow grafts are currently the preferred regimen for HSCT in MS for a number of reasons: there is no risk of GVHD and the risk of infection is lower as there is no ongoing post-HSCT immune suppression. Long-term data from small trials and large international registries support the role for autologous HSCT in MS. The European Bone Marrow Transplant Registry (EBMTR) and the Consortium for International Bone Marrow Transplant Research (CIBMTR) have documented more than 1200 patients undergoing transplantation over the last 20 years.

\section{HSCT IN MS: OLDER TRIALS AND MODERN EXPERIENCE}

Initially, HSCT was chosen for patients with more severe forms of MS, mainly including patients who had long-standing disease and were already severely disabled. In retrospect, it is hard to see where the benefit might lie, given that the target of such treatment is ongoing inflammation, which was likely long over before these patients were treated. The studies were smallphase I/II single-center or multicenter studies that at least helped to establish the safety of the technique. The characteristics of patients treated in those early trials were significantly different than those currently considered for HSCT. The majority of the early patients had advanced disease with high Expanded Disability Status Scale (EDSS) scores (sometimes as high as 9), and most had primary or secondary progressive disease with only a small fraction of relapsing remitting patients (Atkins 2010; Radaelli et al. 2014; Currò and Mancardi 2016). Historically, at that point in time, there were a limited number of disease-modifying drugs available or only low-level immunosuppression was available, so patients were offered HSCT as a last-resort intervention or through compassionate access.

Contemporary studies of HSCT in MS have helped to validate HSCT in MS as a legitimate therapeutic option. Recently, multiple prospective clinical trials and long-term follow-up studies highlighting favorable outcomes of HSCT with increasingly acceptable morbidity and mortality have been published. A meta-analysis performed by Sormani et al. (2017) summarized the evidence of HSCT in MS from studies published between 1995 and 2016. Data from 764 patients reported the association of lower disease progression rate and treatment-related mortality (TRM) in patients with relapsing remitting MS (RRMS) versus secondary progressive MS (SPMS). More disabled patients had higher TRM. An interesting finding was the analysis of NEDA (no evidence of disease activity) reported in a group of patients. Despite different investigators using variable terms in the trials (event-free survival [EFS] or disease activity-free survival [DFS]), the premise is similar to NEDA. The proportion of patients who achieved NEDA at 5-year postHSCT was $67 \%$, which is higher than in any clinical trial of disease-modifying treatment (DMT) for MS to date (Sormani et al. 2016).

Muraro et al. (2017) assessed long-term data of HSCT recipients between 1995 and 2006 and recently reported that transplant-related factors are associated with better outcomes. Relapsing subtypes of MS, younger age at time of transplant, lower pretransplant disability scores, and failure of no more than two DMTs were linked with better prognosis and overall survival.

The Swedish cohort included very active patients with a mean annualized rate of $4.8 \mathrm{ob}$ served in the RRMS subgroup in the pretransplant year and reported NEDA values of $78 \%$ at 2 years and $68 \%$ at 5 years. The Halt MS trial documented a NEDA or EFS of $69.2 \%$ at 5 years.

Data from prospective single-arm trials as well as the ASTIMS (Autologous Hematopoietic Stem Cell Transplantation trial in MS) support the positive results of HSCT outcomes despite marked differences in inclusion criteria, study design, conditioning and mobilization regimens, and follow-up procedures (Table 1) (Londoño and Mora 2016). 
Stem Cell Treatment of MS

Table 1. Contemporary trials of HSCT in multiple sclerosis (MS)

\begin{tabular}{|c|c|c|c|c|c|}
\hline & \multicolumn{5}{|c|}{ References } \\
\hline & $\begin{array}{l}\text { Mancardi et al. } \\
2015 \\
\end{array}$ & $\begin{array}{l}\text { Nash et al. } \\
2017\end{array}$ & $\begin{array}{l}\text { Burt et al. } \\
2015\end{array}$ & $\begin{array}{l}\text { Shevchenko et al. } \\
2015\end{array}$ & $\begin{array}{c}\text { Atkins et al. } \\
2016\end{array}$ \\
\hline Type of trial & $\begin{array}{l}\text { Phase II, } \\
\text { multicenter/ } \\
\text { randomized } \\
\text { (HSCT vs. } \\
\text { Mx) (Italy- } \\
\text { Spain) }\end{array}$ & $\begin{array}{l}\text { Phase II, } \\
\text { multicenter/ } \\
\text { prospective, } \\
\text { open-label, } \\
\text { single-arm } \\
\text { (United States) }\end{array}$ & $\begin{array}{l}\text { Open-label, } \\
\text { single center } \\
\text { (United States) }\end{array}$ & $\begin{array}{l}\text { Phase II, single } \\
\text { center (Russian } \\
\text { Federation) }\end{array}$ & $\begin{array}{l}\text { Phase II, single } \\
\text { arm } \\
\text { (Canada) }\end{array}$ \\
\hline $\begin{array}{c}\text { Number of } \\
\text { patients }\end{array}$ & $\begin{array}{c}21 \text { (9 HSCT arm, } \\
12 \mathrm{Mx} \mathrm{arm)}\end{array}$ & 24 & 145 & 95 & 24 \\
\hline MS type & $\begin{array}{l}\text { RRMS: } 33 \% \\
\text { SPMS: } 67 \%\end{array}$ & RRMS: $100 \%$ & $\begin{array}{l}\text { RRMS: } 81.4 \% \\
\text { SPMS: } 18.6 \%\end{array}$ & $\begin{array}{l}\text { RRMS: } 44 \% \\
\text { SPMS: } 37 \% \\
\text { PPMS: } 19 \%\end{array}$ & $\begin{array}{l}\text { RRMS: } 50 \% \\
\text { SPMS: } 50 \%\end{array}$ \\
\hline $\begin{array}{l}\text { Mean age (range) } \\
\text { in years }\end{array}$ & $35.5(19-46)$ & $38(27-53)$ & $36(18-60)$ & $35(18-55)$ & $34(24-45)$ \\
\hline $\begin{array}{l}\text { Median EDSS } \\
\text { (range) }\end{array}$ & $6(5.5-6.5)$ & $4.5(3.0-5.5)$ & $4.0(3.0-5.5)$ & $3.5(1.5-8)$ & $5.0(3.0-6.0)$ \\
\hline $\begin{array}{l}\text { Median disease } \\
\text { duration } \\
\text { (range) in } \\
\text { years }\end{array}$ & $10.2(2-23)$ & $\begin{array}{l}<15 \text { years } \\
\quad 4.9(0.6-12)\end{array}$ & $5(0.75-22)$ & $5(0.5-24)$ & $5.8(1.3-11.2)$ \\
\hline $\begin{array}{c}\text { Inflammation in } \\
\text { baseline MRI }\end{array}$ & $100 \%$ of patients & $42 \%$ of patients & $57.9 \%$ of patients & $40 \%$ of patients & $\begin{array}{l}87.5 \% \text { of } \\
\text { patients }\end{array}$ \\
\hline $\begin{array}{l}\text { Conditioning } \\
\text { regimen }\end{array}$ & $\begin{array}{l}\text { Mitoxantrone } \\
\text { versus } \\
\text { intermediate- } \\
\text { intensity } \\
\text { BEAM + ATG }\end{array}$ & $\begin{array}{l}\text { Intermediate- } \\
\text { intensity } \\
\text { BEAM + ATG }\end{array}$ & $\begin{array}{l}\text { Low-intensity Cy } \\
\text { with } \\
\text { alemtuzumab } \\
\text { or ATG }\end{array}$ & $\begin{array}{l}\text { Low-intensity } \\
\text { modified } \\
\text { BEAM }\end{array}$ & $\begin{array}{l}\text { High-intensity } \\
\text { (busulphan, } \\
\text { Cy, and } \\
\text { ATG) }\end{array}$ \\
\hline $\begin{array}{l}\text { Treatment- } \\
\text { related } \\
\text { mortality }\end{array}$ & $0 \%$ & $0 \%$ & $0 \%$ & $0 \%$ & $4.2 \%$ \\
\hline \multirow[t]{2}{*}{$\begin{array}{l}\text { Outcome } \\
\text { measures }\end{array}$} & $\begin{array}{l}\text { Reduction of T2 } \\
\text { lesions of } 79 \% \\
\text { and } 100 \% \\
\text { resolution of } \\
\text { enhancing } \\
\text { lesions in } \\
\text { HSCT arm }\end{array}$ & $\begin{array}{l}\text { EFS: } 69.2 \% \\
\text { RFS: } 86.9 \% \\
\text { MFS: } 86.3 \% \\
\text { PFS: } 91.3 \%\end{array}$ & $\begin{array}{l}\text { EFS/DFS: } 68 \% \\
\text { disease } \\
\text { activity-free } \\
\text { survival } \\
\text { RFS: } 80 \% \\
\text { PFS: } 87 \%\end{array}$ & EFS: $80 \%$ & $\begin{array}{l}\text { DFS/EFS: } \\
\text { 69.3\% } \\
\text { RFS: } 100 \% \\
\text { MFS: } 100 \%\end{array}$ \\
\hline & $\begin{array}{l}\text { Reduction in } \\
\text { ARR: } 0.6 \text { for } \\
\text { Mx and } 0.19 \\
\text { for HSCT-p: } \\
0.026, \text { no } \\
\text { difference in } \\
\text { disability } \\
\text { progression }\end{array}$ & & $\begin{array}{l}\text { Reversal or } \\
\text { progression in } \\
\text { disability } \\
\text { (measured by } \\
\text { change in } \\
\text { EDSS score of } \\
1.0 \text { or greater) }\end{array}$ & & \\
\hline Follow-up & 4 years & 5 years & 5 years & 5.1 years & 6.7 years \\
\hline $\begin{array}{l}\text { Evidence of } \\
\text { improvement }\end{array}$ & Not assessed & Yes & Yes & Yes & Yes \\
\hline
\end{tabular}


C.A. Rush et al.

Table 1. Continued

\begin{tabular}{|c|c|c|c|c|c|}
\hline & \multicolumn{5}{|c|}{ References } \\
\hline & $\begin{array}{c}\text { Mancardi et al. } \\
2015\end{array}$ & $\begin{array}{l}\text { Nash et al. } \\
2017\end{array}$ & $\begin{array}{l}\text { Burt et al. } \\
2015\end{array}$ & $\begin{array}{l}\text { Shevchenko et al. } \\
2015\end{array}$ & $\begin{array}{l}\text { Atkins et al. } \\
2016\end{array}$ \\
\hline $\begin{array}{l}\text { EDSS } \\
\text { improvement? }\end{array}$ & & $\begin{array}{l}\text { EDSS score } \\
\text { improvement } \\
\text { (decrease by } \\
\text { more than or } \\
=0.5 \text { ) in } \\
62.5 \% \text { of } \\
\text { patients }\end{array}$ & $\begin{array}{l}64 \% \text { of RRMS } \\
\text { had decrease } \\
\text { in EDSS score } \\
\text { of more than } \\
\text { or }=1.0 \text { points } \\
\text { (4 years)- } \\
52 \% \text { at } 5 \text { years } \\
\text { (NS) }\end{array}$ & $\begin{array}{l}47 \% \text { EDSS } \\
\text { improvement } \\
\text { of at least } 0.5 \\
\text { points }\end{array}$ & $\begin{array}{l}70 \% \text { of } \\
\text { patients had } \\
\text { stable EDSS } \\
\text { with } 35 \% \text { of } \\
\text { patients } \\
\text { with } \\
\text { sustained } \\
\text { EDSS } \\
\text { improve- } \\
\text { ment }\end{array}$ \\
\hline $\begin{array}{l}\text { Other scores/ } \\
\text { scales } \\
\text { improvement? }\end{array}$ & & $\begin{array}{l}\text { Trend in } \\
\text { MSFC (MS } \\
\text { functional } \\
\text { composite } \\
\text { score), } \\
\text { improvement } \\
\text { at } 3 \text { years but } \\
\text { not sustained } \\
\text { at } 5 \text { years }\end{array}$ & $\begin{array}{l}\text { Nine-hole peg } \\
\text { test, timed } \\
\text { 25-ft walk, and } \\
\text { MFSC showed } \\
\text { improvement }\end{array}$ & $\begin{array}{l}\text { Quality of life } \\
\text { (QoL) (SF-36) } \\
\text { parameters } \\
\text { showed } \\
\text { improvement }\end{array}$ & $\begin{array}{l}\text { Brain atrophy } \\
\text { slowed } \\
\text { down to } \\
\text { normal } \\
\text { aging rate }\end{array}$ \\
\hline
\end{tabular}

Some trials report event-free survival (EFS), which is comparable but not identical to no evidence of disease activity (NEDA). Others use disease activity-free survival (DFS), which is a composite of relapse-free survival (RFS), magnetic resonance imaging (MRI), activity-free survival (MFS), and progression-free survival (PFS).

HSCT, Hematopoietic stem cell transplantation; Mx, mitoxantrone; RRMS, relapsing remitting MS; SPMS, secondary progressive MS; PPMS, primary progressive MS; Cy, cyclophosphamide; ARR, annualized relapse rate; EDSS, Expanded Disability Status Scale; NS, not significant; SF-36, 36-item short form health survey.

\section{PATIENT SELECTION}

Patient selection for higher efficacy MS treatments is crucial, but this becomes more critical when considering the option of HSCT. Patients deemed to be good candidates for HSCT need to undergo a much stricter selection process. Some important patient characteristics that need to be addressed are age, duration of disease, MS type, comorbidities, pregnancy desire, prior failure of DMT, personal preference, risk tolerance, geographical parameters, access to other treatments, and funding options, among others. Given that the target of HSCT is the relentless inflammatory disease that typically is unable to be controlled using current DMT, eligible patients should have readily demonstrable evidence of ongoing inflammation. These would include frequent clinical relapses and radiolog- ical confirmation of new or enlarging T2 lesions or enhancing lesions. Typical patients will still have some evidence of relapsing disease, although highly inflammatory early primary progressive disease may be considered as well. Usually longer disease duration is directly related to a higher chance of having accrued more disability as the natural history of the disease shifts from a mainly inflammatory to a more degenerative process; so, ideally, patients should be considered if they have only had no more than 5-10 years of disease.

The choice of younger patients, earlier in their course of disease with less disability along with actively inflammatory disease has resulted in better outcomes with HSCT than had been seen in the earlier studies. In fact, there has even been evidence of recovery, remarkable at times, with improvement of some acquired disabilities. 
Despite this, it would seem rather futile to use HSCT in an older, more advanced patient with little to no demonstrable inflammation in the hope of reversing the disease process. This is because we believe that the recovery is caused by freeing up diseased tissue from the ongoing inflammation that may have been impeding a normal recovery process. Long-standing, fixed, noninflammatory lesions would not be expected to recover with a potent anti-inflammatory therapy. We do, however, reserve the possibility that the cells used to reestablish a normal immune system might be capable of more in terms of some neuroregenerative effects, although this has been difficult to establish in human studies.

It can be difficult to determine which patients may be the best candidates for HSCT, but most would be considered to have some form of aggressive MS (AMS). These patients typically have poor prognostic factors (Table 2 ), and face unrelenting disease activity and progression. Common features of this subgroup of patients are the early accrual of disability asso- ciated with frequent and severe relapses (often with partial recovery) and very active magnetic resonance imaging (MRI) scans, both T2 and enhancing lesions in follow-up scans. Earlier trials included patients with high EDSS scores. Most likely, an EDSS of 6.0 or higher harbingers unfavorable outcomes. Hence, we propose a less stringent definition for AMS suggesting an EDSS of 4.0 to try to capture "salvageable patients" with repair and recovery potential (Rush et al. 2015).

The EBMTR working group has suggested in their guidelines to include (Saccardi et al. 2012):

- RRMS patients who show high clinical and MRI inflammatory activity with rapid deterioration despite use of one or more conventional treatment;

- SPMS patients or transitional MS with evidence of inflammatory activity manifested by relapses and MRI lesion evolution on subsequent scans, and increased in disability in the previous year with EDSS upper limit of 6.5;

Table 2. Prognostic factors for aggressive multiple sclerosis

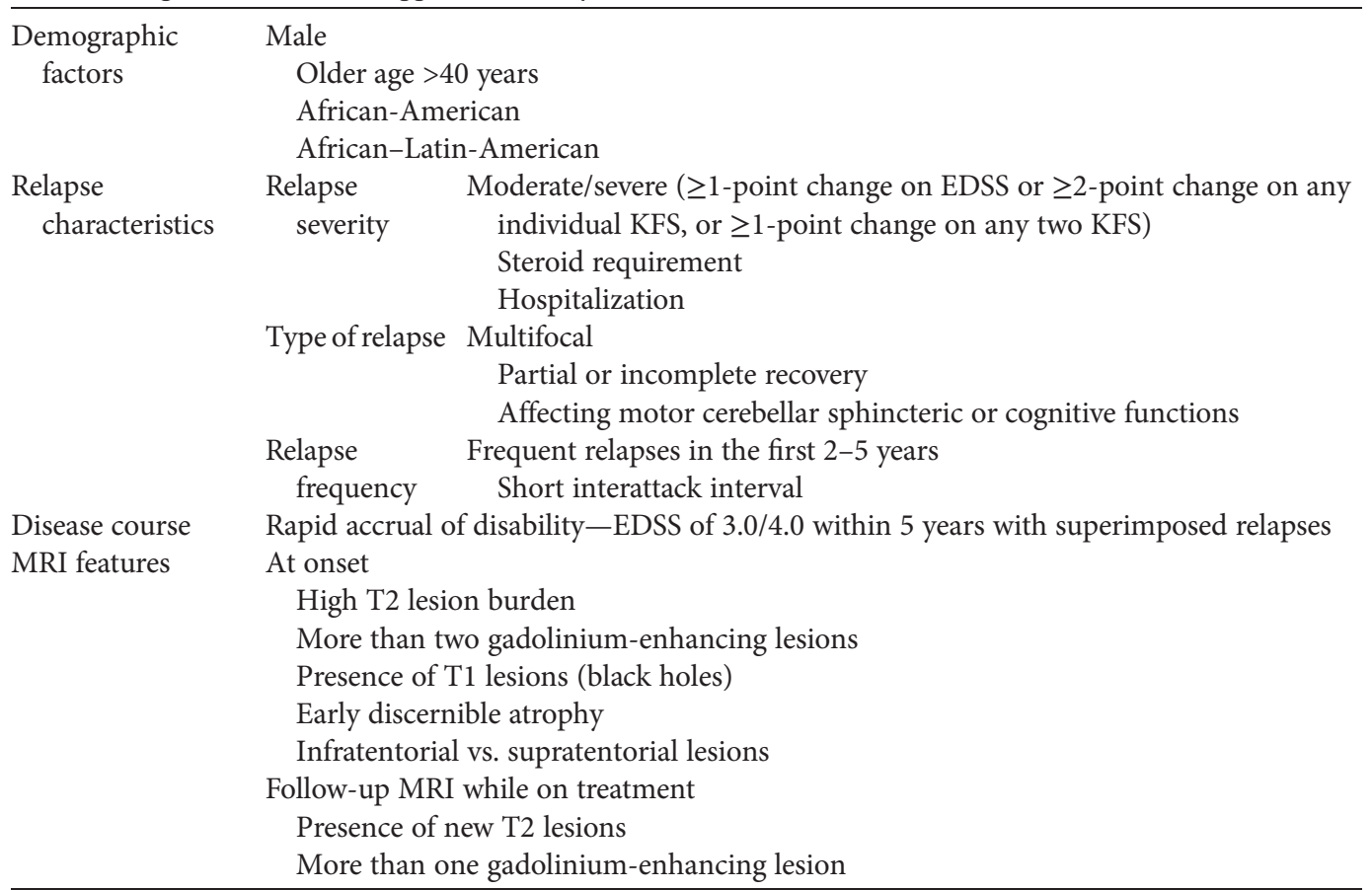

Table from data in Rush et al. 2015; modified, with permission, from the authors.

EDSS, Expanded Disability Status Scale; KFS, Kurtzke Functional System; MRI, magnetic resonance imaging. 
C.A. Rush et al.

- Patients with malignant (Marburg) forms usually have severe disability scores because of the aggressive and rapid course. The upper limit of 6.5 is not applicable and would censor some eligible candidates.

Most patients in HSCT trials have failed multiple agents, translating into longer disease duration and higher disability scores. Higher disability scores before HSCT and longer times at higher EDSS levels have been associated with poorer outcomes and, more importantly, a higher risk of morbidity and mortality, as shown in some of the earlier studies. This does not necessarily apply to previously described malignant MS patients who, despite rapidly reaching high disability scores, can still show remarkable recovery (Mancardi et al. 2005; Kimiskidis et al. 2008; Fagius et al. 2009). There are no reports of treatment-naive patients undergoing HSCT who are deemed AMS from the outset, warranting some form of "induction" treatment. However, we believe that HSCT plays a role in those patients, as we have experienced very encouraging outcomes in five patients with no previous MS-specific treatments

Previous issues with poor compliance to DMTs, symptomatic medications, and followup recommendations should raise early red flags in the selection process. It is not infrequent that we see patients that, over time, have refused to start DMT because of fear of minor inconvenience or side effects or exaggerated concerns of potential toxicities and request HSCT as a "quick fix." This view has been fueled by sensationalism and, more importantly, untrue claims of "stem cell therapies" without lymphocyte-depleting conditioning regimens in the last 5 years.

The changes in outcomes from earlier trials compared with more recent studies have shown that a better selection of patients can make a big difference, not only in terms of efficacy, but also by reducing morbidity and mortality. The rationale for such selectivity of MS patients compared with patients with hematological malignancies derives from the perception that HSCT is an extreme treatment for a chronic, nonfatal condition. There are still important ethical qualms within the medical community and skepticism regarding HSCT in the treatment of MS as this paradigm shift is still very provocative.

\section{MS TREATMENT-SPECIFIC ISSUES TO CONSIDER BEFORE HSCT}

Patients with MS who are selected for HSCT require close monitoring in the preparatory phases of pre-HSCT to prevent systemic or MS-related issues (treatment and prevention of relapses and management and optimization of functional deficits and comorbid conditions). We believe it is best to quiet down disease activity to allow patients to recover before undergoing stem cell mobilization. The process of induction with chemotherapeutic agents has been used (mostly cyclophosphamide [Cy], mitoxantrone $[\mathrm{Mx}]$, and cladribine $[\mathrm{Cd}]$ ) and is variable in duration, ranging from 3 to 9 months.

The correct sequencing of therapies is the holy grail of current MS treatment. Previous use of immunosuppressants and unknown long-term safety data of newer agents expose patients to novel side effects and increased longterm toxicity. Most patients would have failed multiple agents, be they second- or third-line agents or even chemotherapeutic agents used off-label. The compounded toxic effects and the order in which different agents are used in MS will allow or preclude the use of newer and more potent interventions, including HSCT.

Whereas the previous use of some agents (platform therapies, teriflunomide and dimethylfumarate $[\mathrm{DMF}]$ ) does not pose a clinical challenge to transition to HSCT, some will definitely be problematic and need extra surveillance. Interferons can cause mild bone marrow suppression and should be stopped about a month before stem cell mobilization. Blood counts should return to normal before starting the mobilization chemotherapy. There is no data showing teriflunomide effects on bone marrow stores but it would be advisable to discontinue it a month before stem cell mobilization.

Mitoxantrone can potentially cause myelodysplasia or leukemia. We recommend that a marrow aspiration and biopsy for morphological and cytogenetic examination be performed dur- 
ing the pretransplant evaluation for patients who have received previous anthracycline. Prolonged suppression of B cells seen with rituximab and ocrelizumab may prevent reconstitution of Bcell population after HSCT, magnifying the risk of severe infections because of the time it takes for $\mathrm{T}$ cells to reconstitute (individual would be left without T-cell and B-cell responses).

Fingolimod and natalizumab (Nz) withdrawal need to be anticipated and risk-mitigation strategies put in place to avoid disease rebound, like bridging therapy with of $\mathrm{Cy}, \mathrm{Mx}$, or parenteral $\mathrm{Cd}$. The oral formulation of $\mathrm{Cd}$ will likely be approved and available in most countries in the imminent future.

It is advisable to rule out silent or incipient progressive multifocal leukoencephalopathy (PML) induced by the prior agent, $\mathrm{Nz}$, fingolimod, or DMF, by performing high-sensitivity John Cunningham (JC) virus polymerase chain reaction (PCR) tests on the cerebrospinal fluid (CSF) before starting chemotherapeutic agents or embarking on HSCT.

\section{TREATMENT SELECTION}

The number of approved therapies for the treatment of MS continues to expand, promising higher efficacy and better clinical outcomes. The ultimate goal of these interventions should be to approach NEDA; however, in clinical practice, NEDA status is not sustained over time (Rotstein et al. 2015) and less than 50\% attain it within 2 years (Sormani et al. 2016).

Despite the current use of potent agents, many patients still experience breakthrough activity, ultimately requiring the use of immunosuppressants in a desperate bid to control the disease. The use of chemotherapeutic agents in the past has taught us a valuable lesson, trading short-lasting efficacy for lifelong cumulative toxicity. People also resort to these treatments because of limited availability or reimbursement of DMT.

The advances in stem cell technology and experience with HSCT allows for use of even higher intensity chemotherapy capable of completely eliminating an incumbent hematopoietic and immune system, but would also re- sult in long-lasting or permanent severe pancytopenia that would ultimately predispose to fatal complications. It is not possible to survive without a functioning hematopoietic/immune system, but the advent of hematopoietic stem cell transplantation that can fully regenerate both systems makes the delivery of these highdose chemotherapy regimens feasible. The resulting immune system seems more tolerant toward the central nervous system (CNS) (by not attacking it anymore). Earlier trials of HSCT in MS included multiple transplantation protocols that were center specific and used variable mobilization and conditioning regimens. Outcome measures and long-term follow-up are only reported for a small proportion of patients. Additionally, the HSCT process was led by hematologists, experts in transplantation, without input from neurologists. Throughout the years, the care of these patients has evolved into a collaborative effort, with scientists around the world striving for evidence-based confirmation of the role and benefit of HSCT in MS treatment.

Another factor in selecting HSCT as a legitimate intervention in MS patients is the favorable outcome and decrease in TRM observed over time. Older trials reported HSCT mortality as high as $20 \%$ (Openshaw et al. 2000a). However, reassuringly, in the procedures performed after 2001, there is a reported decrease in TRM risk of $1.3 \%$ (Mancardi and Saccardi 2008). Newer trials of RRMS (HALT MS) documented no treatment-related death. Additionally, trials using reduced intensity regimens have shown lower mortality rates but also reduced long-term success in preventing new disease activity. Published data from the Swedish trial and Northwestern University cohorts have also reported no HSCT-related casualties. It is tempting to suggest that high-intensity regimens would trade slightly higher toxicity for better long-term efficacy versus low-intensity protocols.

\section{HEMATOLOGICAL-SPECIFIC ISSUES IN HSCT FOR MS}

The HSCT process in MS is similar to the HSCT procedure used for malignant disorders. Fortu- 
C.A. Rush et al.

nately, MS patients who undergo HSCT are usually younger and have less comorbid conditions than patients who have malignant disorders receiving transplantation, translating into a less complicated posttransplant course.

\section{Stem Cell Mobilization}

Hematopoietic stem cells (HSCs) can be harvested from bone marrow through multiple aspirations from the iliac crests under general anesthesia or by apheresis from peripheral blood after mobilization into the circulation. Hematopoietic stem and progenitor cells mobilized from the peripheral blood is the most common source used for patients undergoing HSCT for MS as these collections yield higher numbers of progenitor cells and result in more rapid engraftment reducing the risk of neutropenic infections. Stem cell mobilization is accomplished through the administration of a cytokine, often granulocyte colony-stimulating factor (G-CSF) in combination with Cy or steroids. G-CSF can activate the immune system and flares of MS activity have been reported following its use (Openshaw et al. 2000b). The use of cyclophosphamide or steroids prevents potential worsening of MS activity induced by the GCSF. Additionally, the Cy used during stem cell mobilization resulting in more efficient mobilization will lead to a lower burden of lymphocytes in the graft product and, to some degree, induce disease activity control. Following mobilization into the circulation, the peripheral blood hematopoietic cells are collected by leukapheresis. In our program, this is almost entirely performed using venipuncture. Occasional patients with poor venous access may require a central venous catheter. The HSC graft can be manipulated and/or cryopreserved and stored until the patient is ready for HSC infusion (Mancardi and Saccardi 2008).

Ex vivo graft manipulation can reduce the burden of immune cells, including autoreactive lymphocytes in the graft. Although technology exists to selectively remove $\mathrm{T}$ lymphocyte populations, it is infrequently used. Rather, when selective depletion of immune cells is performed, all immune cells are removed from the graft product using positive selection of hematopoietic stem and precursor cells bearing the selectively expressed CD $34^{+}$surface antigen. Selection is performed using clinical scale devices based on immunomagnetic separation in which the cells in the HSC graft are incubated with an antibody to CD34 covalently bound to a paramagnetic bead. The cell suspension is passed through a column in a magnetic field. The CD34 expressing cells are retained and the other cells (including lymphocytes and monocytes) are washed away. The magnetic field is released allowing collection of purified $\mathrm{CD} 34^{+}$bearing HSC. This procedure is performed in accredited stem cell laboratory facilities associated with stem cell transplant programs.

\section{Conditioning Regimen}

The ultimate objective of the conditioning regimen is to systematically deplete autoreactive immune cells from the bone marrow, peripheral blood, lymphoid tissue, and the CNS to stop ongoing disease activity. A handful of different chemotherapeutic conditioning regimens have been used to deplete immunologic memory driving the MS disease activity. The regimen used tends to vary regionally.

Conditioning regimens can be categorized as high- and low-intensity protocols based on the degree of myelotoxicity and side effects they provoke. Greater immunodepletion results as the intensity of the conditioning regimen increases. Although there have not been direct comparisons of these different HSCT conditioning regimens on MS outcomes, looking across the breadth of studies, it appears that higher intensity regimens may result in more durable disease control but certainly result in greater morbidity, including higher risk of infections and systemic toxicity, in particular affecting the gastrointestinal tract. There is no consensus as to which regimen is superior because of the lack of randomized trials and the very heterogeneous nature of cohort studies, including differences in trial design, outcome measures, patient selection, and length of follow-up.

Historically, conditioning regimens included chemotherapy with total body irradiation 
Stem Cell Treatment of MS

(TBI). These very high-intensity regimens have fallen out of use because of less optimal outcomes, higher risk of progression, and less recovery of disabilities after HSCT (Atkins 2010).

Somewhat less-intense regimens include combination chemotherapy with BCNU, etoposide, cytosine arabinoside (Ara-C) melphalan, and antithymocyte globulin (BEAM + ATG) or busulphan $(\mathrm{Bu})$ in combination with high doses of Cy and ATG (BuCyATG). Busulphan-based regimens may have an advantage over BEAM because of the better penetration of the bloodbrain barrier, allowing for targeting of the CNS immune system and better disease control. Whereas the initial transplants used very high doses of busulphan, doses have been somewhat reduced and the morbidity of BuCyATG is similar to BEAM-ATG. Almost all regimens include antithymocyte globulin as a way of achieving in vivo depletion of $\mathrm{T}$ cells. Because of the long half-life of these antibodies, it also partially will eliminate lymphocytes contaminating the HSC graft product. BEAM has been one of the most frequently used protocols for HSCT in MS, although a more recent survey of HSCT activity shows increasing use of a low-intensity regime, Cy in combination rabbit antithymocyte globulin (Fig. 1).

\section{Stem Cell Infusion, Engraftment, and Recovery}

In the postconditioning phase, patients experience the expected side effects of the chemotherapeutic agents, different degrees of cytopenia, febrile neutropenia with increased risk of infections, variable multiple organ toxicity, and gastrointestinal and hepatic complications. Comprehensive supportive care is critical through this period. The stem cell infusion denotes day 0 of the new immune system and is a relatively simple process that is performed at the bedside with minimal toxicity. Engraftment ensues thereafter between 10 days to 2 weeks and is the process in which grafted cells settle in the bone marrow and start producing replacement blood cells. Full immune reconstitution and patient systemic and neurological convalescence may take 12 months or longer.

\section{SPECIFIC ISSUES IN YOUNG PATIENTS UNDERGOING HSCT}

There are many common but complex aspects encountered by young patients post cancer and HSCT treatment. The AYA (adolescent and young adults) group is a vulnerable population that faces unique challenges when dealing with cancer treatment between the ages of 15 and 39 . Unfortunately, there is a known gap of knowledge in the oncological literature addressing those different domains (Cooke et al. 2011; Bellizzi et al. 2012; Kent et al. 2012; Ramphal et al. 2016). Specifically, there is no data on these issues for MS patients owing to the small number of MS patients treated with HSCT around the world. Hopefully, awareness and more patientcentered research will guide and direct prioritized strategies to manage this population. Most issues can be extrapolated from cancer registries and guidelines of these topics for young adults (Hayes-Lattin 2015). It is important to consider them in MS patients after HSCT.

\section{Financial Concerns}

Financial issues are among the most pressing concerns in the AYA population. They are intricately related to interrupted studies or disrupted careers stemming from acquired disabilities, time to recover from treatment, and residual deficits they may encounter.

Young adults are more likely to be uninsured or to have very limited health insurance because they may be in a transitional state between their parents' insurance and their own. Part-time employment, sometimes the only realistic goal for patients with disabilities, does not provide appropriate health insurance or suitable accommodations.

These patients are also more likely to face financial burden from student loans, consumer debt, and mortgage payments, and risk higher rates of bankruptcy and dependence on welfare assistance.

Missed education or training leads to lack of employment opportunities, lower income, and perpetuates precarious financial matters with a detrimental effect on stress and coping skills. 
C.A. Rush et al.
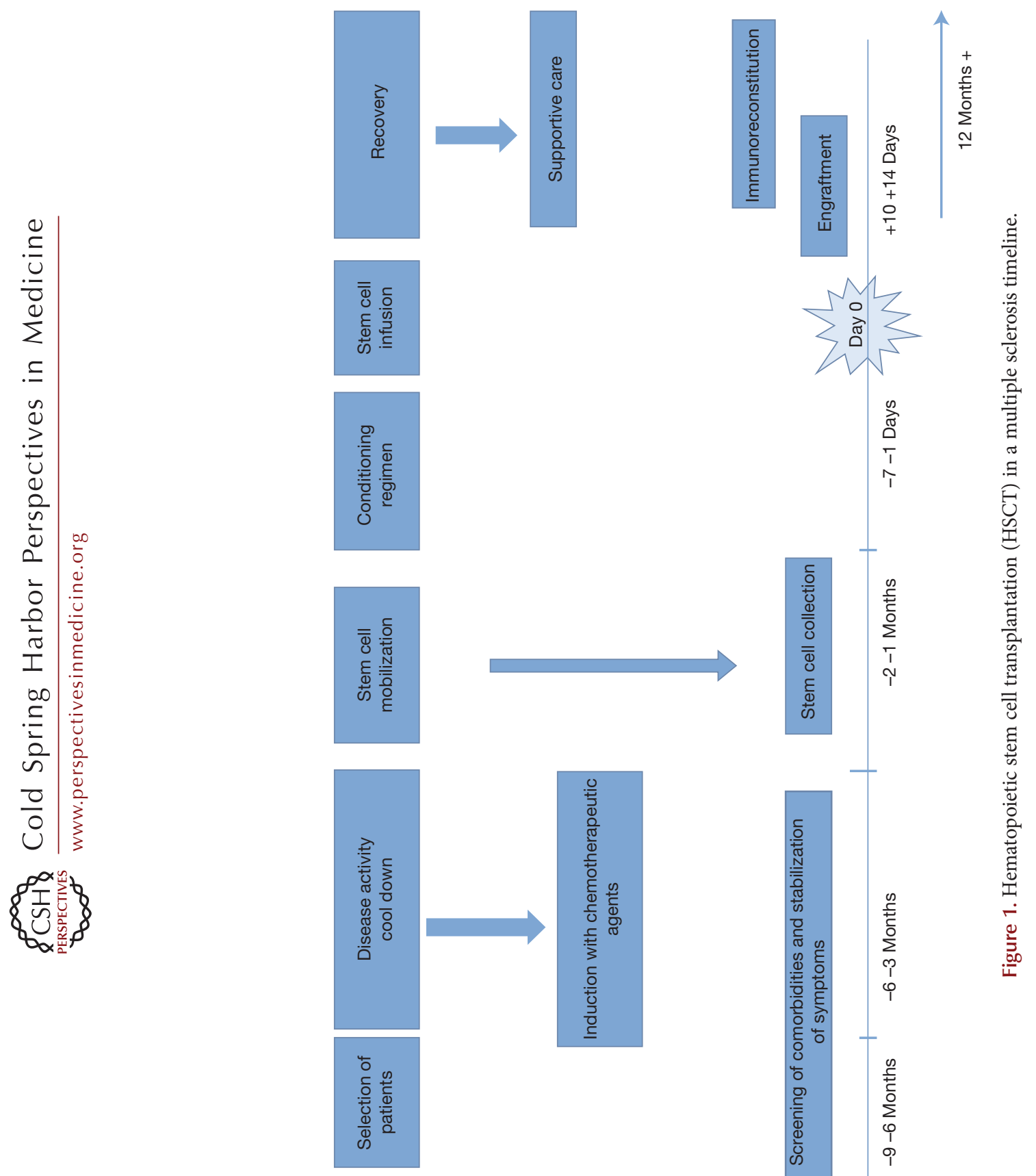
Fertility

Fertility is an important aspect of someone's life. Obviously, patients of reproductive age who are selected to undergo HSCT should have specific education sessions and informed consent about the risk of infertility. Rates of azoospermia and ovarian failure after high doses of conditioning regimens are as high as $90 \%$ and $99 \%$, respectively. Regimens with Cy and ATG may not necessarily cause permanent reproductive issues, but more intensive regimens are likely to result in permanent infertility. Younger age may be associated with lower risk of infertility.

Fortunately, assistive reproductive techniques (ARTs) have evolved dramatically over the last decade. In males, the process is straightforward and requires sperm cryopreservation. Rarely, invasive techniques of sperm retrieval are needed. In women in particular, the process is more complex because hormonal manipulation needs to be planned within a certain time frame with the use of different protocols of gonadotropin-releasing hormone (GnRH). An honest discussion regarding fertility preservation options, views on fertility-enhancing techniques if needed, and alternate parenting (including adoption, surrogacy, and egg donation) need to be had as part of the HSCT selection and screening procedures. Extensive literature from younger patients undergoing cancer treatment for other types of cancer confirms this as an important issue for young patients.

\section{Changes in Roles}

A chronic illness like MS and especially severe forms of the disease receiving HSCT will precipitate shifts in roles and responsibilities for the patient and their family. This would create changes in family dynamics and the inevitable occurrence of conflict. Parenting and caring for young children could be stressful under normal circumstances, but for patients going through HSCT it is particularly challenging because of the possible need for relocation to a different city away from family, isolation during transplant, and ongoing symptoms of fatigue and malaise in the recovery phase. Returning to for- mer roles is also an ongoing concern and a cause for anxiety and feeling of lack of independence for most patients. Going "back to normal" is the ultimate goal but there is no set time frame for it, varying greatly from patient to patient. Role realignment needs to be discussed early on and negotiated with an open and flexible mind to balance the demands of care with other roles such as parent, spouse, sibling, friend, or employee.

\section{SPECIFIC ISSUES IN MS PATIENTS UNDERGOING HSCT}

MS patients who undergo HSCT will encounter particular concerns. One challenge that is specific to MS patients is the functional deficits and disability impairments that are inherent in MS and put them at higher risk of developing particular issues during and after transplantation (Atkins and Freedman 2013).

\section{Triggering of Pseudorelapses}

Fever and infections can easily exacerbate symptoms and trigger pseudorelapses. These usually are transient and typical of the fluctuating symptomatology that patients may have experienced in the past from previous MS attacks and can happen any time during the transplant process. They include worsening spasticity or weakness, increased sensory complaints, exacerbation of neuropathic pain, recurrence of paroxysmal symptoms like Lhermitte's and Uhthoff's phenomena, thoracic MS hug, and others. The treatment of these symptoms is supportive and should focus on patient reassurance, hydration, analgesia, sleeping aids, and spiritual or psychological support. Thorough neurological examination and frequent assessment during HSCT and in the recovery phase are crucial to differentiate these manifestations of pseudoattacks from true MS relapses, because unnecessary treatment with steroids may contribute to a deeper degree of immunosuppression, increasing the chance of infection and heightened patient anxiety. 
C.A. Rush et al.

\section{Infections}

MS patients are more predisposed to have urinary tract infections owing to the high prevalence of neurogenic bladder symptoms and the frequent use of in-dwelling catheters to minimize cyclophosphamide-related hemorrhagic cystitis. By the same token, the risk of developing hemorrhagic cystitis is higher in these patients owing to altered bladder function. Viral infection, in particular reactivation of certain herpes viruses, including varicella zoster virus, human herpes virus, cytomegalovirus, and EpsteinBarr virus, is not uncommon and the latter has also been linked with some lymphoproliferative disorders reported in patients treated with ATG or $\mathrm{CD}_{3}{ }^{+}$grafts.

\section{Secondary Autoimmune Disorders}

Secondary autoimmune diseases (SADs) have been reported after HSCT in autoimmune diseases in $~ 9 \%$ of the studied population (Daikeler et al. 2011). Most were autoimmune thyroiditis with more severe disorders like autoimmune cytopenias occurring less frequently. Burman et al. (2014) reported $8.3 \%$ of the Swedish patients developed SAD, whereas Atkins et al. (2016) described an incidence of $26 \%$. Loh et al. (2007) described two cases of idiopathic thrombocytopenic purpura among $41 \mathrm{MS}$ patients (4.8\%). Transplant protocols using alemtuzumab report higher autoimmunity than if ATG is used.

\section{Worsening of Physical Deficits}

MS patients who undergo HSCT are frequently individuals who have had severe relapses with incomplete recovery and experience moderate degrees of residual physical and mobility deficits. They are at higher risk of worsening disability because of significant deconditioning and myopathic manifestations, chemotherapy-induced cachexia, and drug neurotoxicity. Some patients who are moderately disabled may become further debilitated and require inpatient stay in rehabilitation units to recover the previous baseline of functioning.

Experience from early trials when severely disabled patients were transplanted attest to this observation. Physical and occupational therapies need to be instituted in the screening phase and maintained during the inpatient period along with dynamic reassessment throughout the recovery process.

\section{Cognitve Issues and Fatigue}

Fatigue is a very common manifestation in the recovery phase posttransplant and can take several months to improve. In MS patients in whom fatigue is a prevalent symptom, the effects can be magnified and more disabling than physical complaints. It is multifactorial and related to the disease itself, the effects of the conditioning regimen, and other drugs used for symptom control during the posttransplant recovery.

MS cognitive symptoms and manifestations, premorbid to HSCT, will most likely worsen in the posttransplant phase, gradually plateau, and then in many circumstances show improvement. "Chemo brain" or "chemo fog" are often terms used to describe cancer treatment-related cognitive impairment. For most patients, its effects are short-lived but for some can be permanent. It is very difficult to discern whether the cognitive deficit and complaints are either related to MS, the treatment, or both. Baseline neurocognitive assessment is crucial in MS patients and will be invaluable in the long-term followup of transplanted individuals.

\section{Sexual Dysfunction}

Sexual dysfunction is common in MS patients, with prevalence as high as 90\% (Kessler et al. 2009) and is directly related to quality of life, depression, and relationships with partners (Foley et al. 2013; Schairer et al. 2014). Most MS patients undergoing HSCT are young $(<45$ years old) and experience longer life expectancy survival than patients with malignant disorders, hence requiring special attention. Sexuality difficulties in HSCT survivors are also frequent and some investigators report that $50 \%$ of male and $80 \%$ of female patients disclose sexual dysfunction posttransplant. The etiology is multifactorial and is caused by hypogonadism secondary to endocrinopathy, psychological factors related 
to depression, anxiety or self-esteem issues, or situational associated with role changes and financial concerns. The presence of systemic symptoms and medication side effects also play an important role. In women, in particular, the advent of early menopause is the major contributor to sexual dysfunction as it triggers a multitude of physical and emotional symptoms. Prompt referral to a women's health specialty clinic is recommended within the first 9 months post-HSCT to address common symptoms experienced by female patients to minimize fatigue and to improve quality of life, including sleep, mood, libido, and activity levels. Early hormone replacement in early menopause is indicated to prevent cardiovascular complications and osteoporosis.

\section{Fertility Issues in MS}

As MS affects patients at their most fertile age, and women twice as much as men, fertility-related issues need to be appropriately addressed. The discussion should ideally take place when young women are first diagnosed to estimate pregnancy desire and family planning time frame. These patients can also face fertility difficulties related to prior DMTs.

Different protocols of ART have been used in patients with MS. GnRH agonists or antagonists are used to down-regulate the hypothalamic-pituitary gland axis and to control luteinizing hormone (LH) surge and ovulation. These frequently need to be timed and synchronized over several menstrual cycles (Hellwig et al. 2017). However, in the context of HSCT in MS, many of these patients do not have much time to contemplate these options because of the aggressive nature of their disease. Additionally, there is evidence that both GnRH protocols cause exacerbation of disease activity, both clinically and radiologically, triggering relapses and new lesions (Correale et al. 2012; Michel et al. 2012; Hellwig and Correale 2013).

\section{Employment Issues and Vocational Training}

Patients with severe MS have resigned themselves to be unemployed or are afraid of taking new challenges. Many are out of the workforce for a long time or have decided against undertaking postsecondary education or skills training because of MS symptoms.

Improvement in disability and quality-oflife scores seen in many transplanted patients has been very reassuring. Atkins et al. (2016) reported that $37 \%$ of patients were able to return to school or resume employment after HSCT.

Formal vocational counseling and rehabilitation are extremely important and frequently neglected in this special population of patients. They should be proactively offered once patients have recovered and stabilized both systemically and neurologically. School and work integration assistance strategies are crucial and have shown to be empowering to patients after HSCT and cancer treatment and have given them a renewed sense of purpose.

\section{CONCLUDING REMARKS}

Development of a phase III, prospective controlled multicenter trial comparing autologous HSCT with conventional high-potency DMT with planned long-term follow-up of patients is needed to assess the ultimate efficacy and safety of HSCT. The role of HSCT in changing the natural history of MS is promising as observed in progression-free survival curves but systematic and critical analysis is warranted. Furthermore, it will hopefully address questions about repair mechanisms and which patients may have the best potential for improvement.

The selection of centers with expertise in both hematology and stem cell transplantation and MS "know-how" is critical, because these patients have particular characteristics that separate them from the regular typical patients receiving treatment for their MS. This cannot be emphasized enough in an era of increasing unregulated centers promising stem cell treatments to treat multiple neurological and systemic diseases without the required infrastructure, expertise, and scientific support needed to perform such a complex intervention. Patients are continuously bombarded with offers of offshore locations to receive HSCT and stem cell therapy, overestimating the benefits of the procedure and 
C.A. Rush et al.

many times promising a guaranteed outcome, failing to disclose morbidity and mortality.

\section{REFERENCES}

Atkins H. 2010. Hematopoietic SCT for the treatment of multiple sclerosis. Bone Marrow Transplant 45: 16711681.

Atkins HL, Freedman MS. 2013. Hematopoietic stem cell therapy for multiple sclerosis: Top 10 lessons learned. Neurotherapeutics 10: 68-76.

Atkins HL, Bowman M, Allan D, Anstee G, Arnold DL, BarOr A, Bence-Bruckler I, Birch P, Bredeson C, Chen J, et al. 2016. Immunoablation and autologous haemopoietic stem-cell transplantation for aggressive multiple sclerosis: A multicenter single-group phase 2 trial. Lancet 388: 576-585.

Bellizzi KM, Smith A, Schmidt S, Keegan TH, Zebrack B, Lynch CF, Deapen D, Shnorhavorian M, Tompkins BJ, Simon M, et al. 2012. Positive and negative psychosocia impact of being diagnosed with cancer as an adolescent or young adult. Cancer 118: 5155-5162.

Burman J, Iacobaeus E, Svenningsson A, Lycke J, Gunnarsson M, Nilsson P, Vrethem M, Fredrikson S, Martin C Sandstedt A, et al. 2014. Autologous haematopoietic stem cell transplantation for aggressive multiple sclerosis: The Swedish experience. J Neurol Neurosurg Psychiatry 10: 1116-1121.

Burt RK, Balabanov R, Han X, Sharrack B, Morgan A, Quigley K, Yaung K, Helenowski IB, Jovanovic B, et al. 2015 . Association of nonmyeloablative hematopoietic stem cell transplantation with neurological disability in patients with relapsing-remitting multiple sclerosis. JAMA $\mathbf{3 1 3}$ 275-284.

Cooke L, Chung C, Grant M. 2011. Psychosocial care for adolescents and young adult haematopoietic cell transplant patients. J Psychosoc Oncol 29: 394-414.

Correale J, Farez MF, Ysrraelit MC. 2012. Increase in multiple sclerosis activity after assisted reproduction technology. Ann Neurol 72: 682-694.

Currò D, Mancardi GL. 2016. Autologous hematopoietic stem cell transplantation in multiple sclerosis: 20 years of experience. Neurol Sci 37: 857-865.

Daikeler T, Labopin M, Di Gioia M, Abinun M, Alexander T, Miniati I, Gualandi F, Fassas A, Martin T, Schwarze CP, et al. 2011. Secondary autoimmune diseases occurring after HSCT for an autoimmune disease: A retrospective study of the EBMT Autoimmune Disease Working Party. Blood 118: 1693-1698.

Fagius J, Lundgren J, Oberg G. 2009. Early highly aggressive MS successfully treated by hematopoietic stem cell transplantation. Mult Scler 15: 229-237.

Fassas A, Anagnostopoulos A, Kazis A, Kapinas K, Sakellari I, Kimiskidis V, Tsompanakou A. 1997. Peripheral blood stem cell transplantation in the treatment of progressive multiple sclerosis: First results of a pilot study. Bone Marrow Transplant 8: 631-638.

Foley FW, Zemon V, Campagnolo D, Marrie RA, Cutter G, Tyry T, Beier M, Farrell E, Vollmer T, Schairer L. 2013. The Multiple Sclerosis intimacy and sexuality question-
naire-Re-validation and development of a 15-item version with a large US sample. Mult Scler 19: 1197-1203.

Hayes-Lattin B. 2015. Adolescent and young adult concerns. In Blood and marrow transplant handbook, 2nd ed. (ed. Maziarz RT, Shubach Slater S), pp. 99-105. Springer, New York.

Hellwig K, Correale J. 2013. Artificial reproductive techniques in multiple sclerosis. Clin Immunol 149: 219-224.

Hellwig K, Brzosko B, Airas L, Smith EK. 2017. Fertility and assisted reproductive techniques in women with MS. In Health issues in women with multiple sclerosis (ed. Houtchens MK, Sadovnick D), pp. 9-17. Springer, New York.

Kent EE, Parry C, Montoya MJ, Sender LS, Morris RA, Anton-Culver H. 2012. "You're too young for this": Adolescent and young adults' perspectives on cancer survivorship. J Psychosoc Oncol 30: 260-279.

Kessler T, Fowler C, Panicker J. 2009. Sexual dysfunction in multiple sclerosis. Exp Rev Neurotherapeut 9: 341-350.

Kimiskidis V, Sakellari I, Tsimourtou V, Kapina V, Papagiannopoulos S, Kazis D, Vlaikidis N, Anagnostopoulos A, Fassas A. 2008. Autologous stem-cell transplantation in malignant multiple sclerosis: A case with a favorable long-term outcome. Mult Scler 14: 278-283.

La Nasa G, Littera R, Cocco E, Battistini L, Marrosu MG, Contu L. 2004. Allogeneic hematopoietic stem cell transplantation in a patient affected by large granular lymphocyte leukemia and multiple sclerosis. Ann Hematol 83: 403-405.

Loh Y, Oyama Y, Statkute L, Quigley K, Yaung K, Gonda E, Barr W, Jovanovic B, Craig R, Stefoski D, et al. 2007. Development of a secondary autoimmune disorder after hematopoietic stem cell transplantation for autoimmune diseases: Role of conditioning regimen used. Blood 109: 2643-2548.

Londoño AC, Mora CA. 2016. Autologous bone marrow transplantation in multiple sclerosis: Biomarker relevance for patient recruitment and follow up. JClin Cell Immunol 7: 455 .

Mancardi G, Saccardi R. 2008. Autologous haematopoietic stem-cell transplantation in multiple sclerosis. Lancet Neurol 7: 626-636.

Mancardi GL, Murialdo A, Rossi P, Gualandi F, Martino G, Marmont A, Ciceri F, Schenone A, Parodi RC, Capello E, et al. 2005. Autologous stem cell transplantation as rescue therapy in malignant forms of multiple sclerosis. Mult Scler 11: 367-371.

Mancardi GL, Sormani MP, Gualandi F, Saiz A, Carreras E, Merelli E, Donelli A, Lugaresi A, Di Bartolomeo P, Rottol MR, et al. 2015. Autologous hematopoietic stem cell transplantation in multiple sclerosis: A phase II trial. $\mathrm{Neu}$ rology 84: 981-988.

Mandalfino P, Rice G, Smith A, Klein JL, Rystedt L, Ebers GC. 2000. Bone marrow transplantation in multiple sclerosis. J Neurol 247: 691-695.

McAllister LD, Beatty PG, Rose J. 1997. Allogeneic bone marrow transplant for chronic myelogenous leukemia in a patient with multiple sclerosis. Bone Marrow Transplant 19: 395-397.

Michel L, Foucher Y, Vukusic S, Confavreux C, de Sèze J, Brassat D, Clanet M, Clavelou P, Ouallet JC, Brochet B, et 
al. 2012. Increased risk of multiple sclerosis relapse after in vitro fertilization. J Neurol Neurosurg Psychiatry 83: 796-802.

Muraro PA, Pasquini M, Atkins HL, Bowen JD, Farge D, Fassas A, Freedman MS, Georges GE, Gualandi F, Hamerschlak N, et al. 2017. Long-term outcomes after autologous hematopoietic stem cell transplantation for multiple sclerosis. JAMA Neurol 74: 459-469.

Nash RA, Hutton GJ, Racke MK, Popat U, Devine SM, Steinmiller KC, Griffith LM, Muraro PA, Openshaw H, Sayre PH, et al. 2017. High-dose immunosuppressive therapy and autologous HCT for relapsing-remitting MS. Neurology 88: 842-852.

Openshaw H, Lund BT, Kashyap A, Atkinson R, Sniecinski I, Weiner LP, Forman S. 2000a. Peripheral blood stem cell transplantation in multiple sclerosis with busulfan and cyclophosphamide conditioning: Report of toxicity and immunological monitoring. Biol Blood Marrow Transplant 6: 563-575.

Openshaw H, Stuve O, Antel JP, Nash R, Lund BT, Weiner LP, Kashyap A, McSweeney P, Forman S. 2000b. Multiple sclerosis flares associated with recombinant granulocyte colony-stimulating factor. Neurology 54: 2147-2150.

Radaelli M, Merlini A, Greco R, Sangalli F, Comi G, Ciceri F, Martino G. 2014. Autologous bone marrow transplantation for the treatment of Multiple Sclerosis. Curr Neurol Neurosci Rep 14: 478.

Ramphal R, Aubin S, Czaykowski P, De Pauw S, Johnson A, McKillop S, Szwajcer D, Wilkins K, Rogers P; Canadian Task Force on Adolescents and Young Adults with Cancer. 2016. Adolescent and young adult cancer: Principles of care. Curr Oncol 23: 204-209.

Rotstein DL, Healy BC, Malik MT, Chitnis T, Weiner HL. 2015. Evaluation of no evidence of disease activity in a 7year longitudinal multiple sclerosis cohort. JAMA Neurol 72: $152-158$.
Rush CA, MacLean HJ, Freedman MS. 2015. Aggressive multiple sclerosis: Proposed definition and treatment algorithm. Nat Rev Neurol 11: 379-389.

Saccardi R, Freedman MS, Sormani MP, Atkins H, Farge D, Griffith LM, Kraft G, Mancardi GL, Nash R, Pasquini M, et al. 2012. A prospective, randomized, controlled trial of autologous haematopoietic stem cell transplantation for aggressive multiple sclerosis: A position paper. Mult Scler 18: 825-834.

Schairer LC, Foley FW, Zemon V, Tyry T, Campagnolo D, Marrie RA, Gromisch ES, Schairer D. 2014. The impact of sexual dysfunction on health-related quality of life in people with multiple sclerosis. Mult Scler 20: 610-616.

Shevchenko JL, Kuznetsov AN, Ionova TI, Melnichenko VY, Fedorenko DA, Kurbatova KA, Gorodokin GI, Novik AA. 2015. Long-term outcomes of autologous hematopoietic stem cell transplantation with reduced-intensity conditioning in multiple sclerosis: Physician's and patient's perspectives. Ann Hematol 94: 1149-1157.

Sormani MP, Muraro PA, Saccardi R, Mancardi GL. 2016. NEDA status in highly active MS can be more easily obtained with autologous hematopoietic stem cell transplantation than other drugs. Multiple Sclerosis J 23: 201-204.

Sormani MP, Muraro PA, Schiavetti I, Signori A, Laroni A, Saccardi R, Mancardi GL. 2017. Autologous hematopoietic stem cell transplantation in multiple sclerosis: A meta-analysis. Neurology 88: 2115-2122.

van Gelder EP, van Bekkum DW. 1993. Treatment of experimental allergic encephalomyelitis in rats with total body irradiation and syngeneic BMT. Bone Marrow Transplant 11: 233-241.

van Gelder M, van Bekkum DW. 1996. Effective treatment of relapsing experimental autoimmune encephalomyelitis with pseudoautologous bone marrow transplantation. Bone Marrow Transplant 18: 1029-1034. 


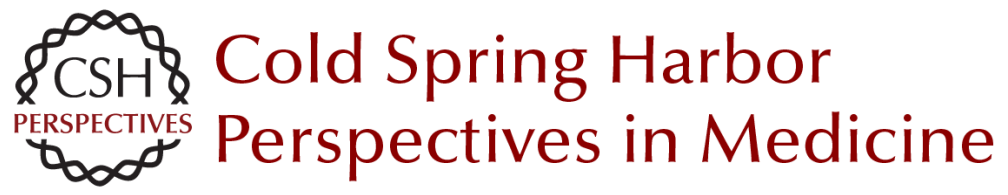

\section{Autologous Hematopoietic Stem Cell Transplantation in the Treatment of Multiple Sclerosis}

Carolina A. Rush, Harold L. Atkins and Mark S. Freedman

Cold Spring Harb Perspect Med 2019; doi: 10.1101/cshperspect.a029082 originally published online April 2, 2018

\begin{tabular}{|c|c|}
\hline \multicolumn{2}{|l|}{ Subject Collection Multiple Sclerosis } \\
\hline $\begin{array}{l}\text { Multiple Sclerosis Pathology } \\
\text { Hans Lassmann }\end{array}$ & $\begin{array}{l}\text { Natalizumab: Perspectives from the Bench to } \\
\text { Bedside } \\
\text { Afsaneh Shirani and Olaf Stüve }\end{array}$ \\
\hline $\begin{array}{l}\text { Regulatory T Cells: From Discovery to } \\
\text { Autoimmunity } \\
\text { Alexandra Kitz, Emily Singer and David Hafler }\end{array}$ & $\begin{array}{l}\text { Daclizumab Therapy for Multiple Sclerosis } \\
\text { Bibiana Bielekova }\end{array}$ \\
\hline $\begin{array}{l}\text { The Multiple Roles of B Cells in Multiple Sclerosis } \\
\text { and Their Implications in Multiple Sclerosis } \\
\text { Therapies } \\
\text { Rui Li and Amit Bar-Or }\end{array}$ & $\begin{array}{l}\text { Lifestyle and Environmental Factors in Multiple } \\
\text { Sclerosis } \\
\text { Lars Alfredsson and Tomas Olsson }\end{array}$ \\
\hline $\begin{array}{l}\text { Autologous Hematopoietic Stem Cell } \\
\text { Transplantation in the Treatment of Multiple } \\
\text { Sclerosis } \\
\text { Carolina A. Rush, Harold L. Atkins and Mark S. } \\
\text { Freedman }\end{array}$ & $\begin{array}{l}\text { Biomarkers in Multiple Sclerosis } \\
\text { Anu Paul, Manuel Comabella and Roopali Gandhi }\end{array}$ \\
\hline $\begin{array}{l}\text { B-Cell Therapies in Multiple Sclerosis } \\
\text { Joseph J. Sabatino, Jr., Scott S. Zamvil and } \\
\text { Stephen L. Hauser }\end{array}$ & $\begin{array}{l}\text { The Evolving Mechanisms of Action of Glatiramer } \\
\text { Acetate } \\
\text { Thomas Prod'homme and Scott S. Zamvil }\end{array}$ \\
\hline $\begin{array}{l}\text { Oral Therapies for Multiple Sclerosis } \\
\text { Simon Faissner and Ralf Gold }\end{array}$ & $\begin{array}{l}\text { Regulation of Astrocyte Functions in Multiple } \\
\text { Sclerosis } \\
\text { Michael A. Wheeler and Francisco J. Quintana }\end{array}$ \\
\hline $\begin{array}{l}\text { Interferon } \beta \text { for Multiple Sclerosis } \\
\text { Dejan Jakimovski, Channa Kolb, Murali } \\
\text { Ramanathan, et al. }\end{array}$ & $\begin{array}{l}\text { Experimental Autoimmune Encephalomyelitis } \\
\text { (EAE) as Animal Models of Multiple Sclerosis (MS) } \\
\text { Simon Glatigny and Estelle Bettelli }\end{array}$ \\
\hline $\begin{array}{l}\text { Alemtuzumab as Treatment for Multiple Sclerosis } \\
\text { Serafeim Katsavos and Alasdair Coles }\end{array}$ & $\begin{array}{l}\text { Neurodegeneration in Progressive Multiple } \\
\text { Sclerosis } \\
\quad \text { Graham Campbell and Don Mahad }\end{array}$ \\
\hline
\end{tabular}

For additional articles in this collection, see http://perspectivesinmedicine.cshlp.org/cgi/collection/ 